EGU2020-3055

https://doi.org/10.5194/egusphere-egu2020-3055

EGU General Assembly 2020

(c) Author(s) 2020. This work is distributed under

the Creative Commons Attribution 4.0 License.

\title{
MOTEDAS Century Database, Part 2: spatial variation of temperature trends: the UP-TO-DATE effect.
}

\author{
Leire Sandonis ${ }^{1}$, Dhais Peña-Angulo ${ }^{2}$, michele Bruneti ${ }^{3}$, Santiago Beguería ${ }^{4}$, and José Carlos \\ Gonzalez-Hidalgo ${ }^{1}$ \\ 1'University Zaragoza, Geography, Geography, Zaragoza, Spain (leiresandonis@unizar.es; jcgh@unizar.es) \\ ${ }^{2}$ Instituto Pirenaico Ecología, CSIC, Zaragoza, Spain \\ ${ }^{3}$ ISAC-CNR, Bologna, Italy \\ ${ }^{4}$ Estación Experimental Aula Dei, CSIC, Zaragoza, Spain (sbegueria@eead.csic.es)
}

We have finished the complete digitalization of Annual Books from the Spanish meteorological service (AEMET) between 1916 to 1949. Data retrieved included monthly means of maximum and minimum temperature. In the present contribution we are going to show the new MOTEDAS_Century dataset (MOnthly TEmperature Dataset of Spain century) which has been performed matching data from the annual books and data from the national climate data bank of AEMET. The amount of stations with temperature data vary from a minimum of 228 (1938) and 2.030 (1994). This length of the time series is sometimes very short. Since we aim to analyse the information with a highest spatial density as possible we decided, instead of reconstructing series, to reconstruct monthly fields independently by using all the information available month to month between 1916 and 2015. Monthly interpolated data were converted to a high-resolution grid (10x10 km) using the Angular Distance Weighting method, resulting into a 5000 pixels grid.

The time series of annual mean temperature in Spanish mainland from 1916 to 2015 shows the well-known pattern of increase during the first decades, a slowdown in the middle of the $20^{\text {th }}$ century, and the final rise since the 1970's, including a final stage without significant trend for the last three decades.

MOTEDAS_Century's annual temperature average series has been compared with other analogous series from BEST (Berkelay Earth Surface Temperature) and SDAT (Spanish Daily Adjusted Temperature Series) datasets, as well as the twentieth century reanalysis for the Iberian Peninsula. The different versions resemble the global pattern, although differences exist particularly during the last three decades. The comparison of the annual mean temperature series with their counterparts in the BEST, AEMET and SDAT databases suggests that processing the newly retrieved information does not modify the behaviour patterns of mean annual temperatures in the Spanish mainland, and that the difference observed among the various sources can be attributed to a combination of effects from the different number of weather stations examined, which is very much higher in MOTEDAS_century, to the local characteristics of stations. The MOTEDAS_century grid in the anomalies format is available on request from the 
authors and will be in future on the website of the CLICES Project (http://clices.unizar.es). 